\title{
Harnessing the power of social media for creativity support: A three-pronged approach
}

\author{
Christian Wagner* \\ School of Creative Media \\ Department of Information Systems \\ City University of Hong Kong, Hong Kong \\ E-mail: iscw@ cityu.edu.hk
}

\section{Ling Jiang}

Department of Information Systems

City University of Hong Kong, Hong Kong

E-mail: lingjiang2@student.cityu.edu.hk

*Corresponding author

\begin{abstract}
The article reviews past approaches to creativity support, differentiating between computer centric and human centric approaches. It identifies shortcomings of past creativity support systems, to propose a new three-pronged approach for creativity support through social media. The approach suggests drawing on collective intelligence for need identification, idea generation, and idea evaluation. Focusing on innovation in business, the article demonstrates how knowledge and creativity can be extracted from social media to facilitate all three activities.
\end{abstract}

Keywords: Creativity; Creativity support; Social media; Idea generation; Collective intelligence; Innovation

Biographical notes: Christian Wagner is Professor in the School of Creative Media and the Department of Information Systems at City University of Hong Kong. He also serves as Associate Dean in the School of Creative Media, and as Associate Provost for Quality Assurance for CityU. Wagner specializes in the development and study of creativity support, collective intelligence, knowledge management, and the use of computer games for learning. He is an award-winning author, multiple teaching award winner, experienced administrator, and software entrepreneur. $\mathrm{He}$ is most recognized for his research on wikis and their impact on organizational performance.

Ling Jiang is a Ph.D. candidate in the Department of Information Systems at City University of Hong Kong. She began her Ph.D. study in 2010. Her research interests include collective intelligence, electronic knowledge management and the behavior of individual in virtual communities. 


\section{Introduction}

Creativity has long been perceived as a mysterious construct, challenging researchers to try and reveal its underlying mechanisms and make full use of them in practice. Some thinkers, such as Sir Francis Galton (1869), concentrated on the investigation of eminent creators and emphasized the effect of genetic determinants of intellectual power on creativity, while others adopted a process perspective to suggest that the potential for creative thinking existed to a greater or lesser degree in everyone, which could be acquired and supported through educational intervention (e.g., Ripple, 1989). Advances in information technology have generated new research interest, and the goal to support creativity by information systems, leading to the development of creativity support systems.

Systems supporting creativity, however, are difficult to build. Past attempts fall into two categories: computer centric and human centric. Based on the assumption that computers can produce creative ideas automatically, computer centric approaches sought to design systems that could independently generate new ideas, or even make original scientific discoveries (Walker, 1987). These attempts brought a clearer understanding concerning the feasibility of machine based creative reasoning; meanwhile they also created much debate about the actual achievements, a debate that requires further exploration. In human centric creativity support systems, people take on the dominant role in the idea generation process, but their activities are enhanced by technology. Thus, the effectiveness of human centric creativity support systems relies on the systems' ability for process improvement, while the outcome is still restrained by individual differences of users. Results therefore - not surprisingly-indicate that individuals with more innate capability may be helped the most, and that the innate creativity may be more important than machine contribution (MacCrimmon \&Wagner, 1994).

While individuals and (small) groups are often thought of as the primary source of intellectual accomplishments including creativity, researchers have gradually recognized the power of large collectives. Surowiecki (2005) pointed out that when individuals in a crowd were appropriately diverse, independent and decentralized, their aggregated decisions would be surprisingly good, better than those made by the smartest person within the crowd. This proposition suggests high potential value residing in distributed collectives of people. While this potential has always existed, only now the low cost of communication via Internet social media makes it feasible for dispersed people to interact across time and space, thus effectively harnessing this potential. The dominance of web applications enabling and promoting collective collaboration, such as Wikipedia, Flickr, Facebook, or Digg, likewise signals the readiness of people to share ideas through social media and collectively aggregate them. In view of the usefulness and feasibility of potential power in social media, it thus appears promising to utilize these collective abilities to stimulate and support creativity. This article systematically explores opportunities for collective creativity enabled by social media.

\subsection{Can Software Enhance Creativity?}

Many people believe that creativity is strictly a human attribute. To them, the view that computers can be creative is thus contradictory. The underlying assumption is that in order to be creative, not just the output has to be considered creative, but also the process must be creative. Randomly or algorithmically produced outcomes, by definition, cannot be creative, no matter how unique. In contrast, this discussion of creativity support systems takes a Turing-machine (Turing, 1937) perspective. Accordingly, the behavior of 
a reasoning system (human or computer) will be judged as creative, if the activities that generate the behavior repeatedly result in outcomes that would be judged as creative by an independent observer. Hence, unrepeatable acts of creativity, i.e., pure luck, will not be considered creative. Yet a repeatable process, whether automated or not, will be considered creative, if the outcomes warrant it.

\subsection{Creative outcomes - A modest definition}

One of the reasons why people frequently challenge the notion of computers being able to create, is that creativity usually invokes images of creative geniuses such as Mozart or $\mathrm{Da}$ Vinci. While these geniuses have been able to repeatedly generate "new to the world" original ideas of great impact, creativity can occur on many levels and with many facets. What is commonly agreed (e.g., Dean, Hender, Rodgers, \& Santanen, 2006; MacCrimmon \& Wagner, 1994; Dacey, 1989; Bessemer \& Treffinger, 1981; Jones, 1971; Jackson \& Messic, 1965) is that a base level of creativity requires performance on three dimensions: originality, implementability, and purpose. Originality is the "newness" of an idea. Implementability is the requirement that the idea can be realized. Hence, for instance a perpetuum mobile, while being highly original, fails this quality of creativity. Purpose requires that the idea has some value, benefits, or usefulness. Hence, useless ideas do not pass the test. Along each of these dimensions, variations are possible, e.g., from very modest originality (new to the inventor only) to great originality (new to everyone). Thus, each creative product may be seen as a feature bundle with some level of originality, implementability, and purpose.

In addition to these three basic dimensions, some researchers have identified additional ones (e.g., Bessemer \& Treffinger, 1981) which recognize special qualities of some ideas. Ideas can be transformational, if they transform a practice, an industry, a culture, and so on. Other ideas are germinal so that their influence grows over time. Disruptive innovations (Christensen \& Overdorf, 2000), such as the mobile phone or digital media, may be seen as satisfying both of these criteria. For the discussion in this article, however, there are no special demands for creativity in terms of germinal or transformational qualities. The focus will be modest, requiring only an enhancement in originality, implementability, and fit for purpose.

The remainder of this article is organized as follows. Section 2 reviews the background and past approaches related to creativity support systems. Our approach to support creativity through collective intelligence via social media is proposed and exemplified in Section 3. Finally, we conclude with a discussion on the limitations and challenges of this proposed approach in Section 4.

\section{Background on creativity support systems}

As mentioned above, prior technology based developments to support creativity and idea generation can be divided into two categories, computer centric and people centric. Machine centric developments (e.g., Michie \& Johnston, 1984), resulting from research in artificial intelligence, have attempted to build "creative machines". The desired result is software that generates creative ideas with little or no human intervention. People centric developments (e.g., MacCrimmon \& Wagner, 1991/92) have sought to enhance the innate creativity of people, either by structuring their work processes, or by providing them with specific ideas known to enhance creative thinking (e.g., Synectics). Each development approach is briefly outlined below. 


\subsection{Machine reasoning approaches based on deduction and induction}

With the dramatic improvements in raw computing power over the years, researchers time and again considered the possibilities to have machines involved in creativity support. Walker (1987) introduced several scientific discovery programs based on machine reasoning. META-DENDRAL functioned as a rule discovery tool for new rules of spectroscopy through deductive reasoning. BACON (Langley, Simon, Bradshaw, \& Zytkow, 1987) re-discovered laws of science like Kepler's Laws by means of data mining. PROSPECTOR accurately predicted the location of a high-grade molybdenum deposit based on initial geologic data and many if-then reasoning rules. These examples demonstrate the power of machine reasoning in creativity support.

These programs" "creativity" resulted largely from two mechanisms, namely (a) their ability to induce rules from noisy data sets, as is nowadays commonplace in data mining systems and (b) their exhaustive pursuit of the reasoning process. As an induction machine, a program extracts rules or patterns from training data, and then applies these rules to general data to discover new knowledge, which in turn is used to expand the initial knowledge repository. The tireless and exhaustive execution of both inductive and deductive approaches finds all possible rules, and then applies them to potentially derive all possibly following conclusions, some of which may be considered creative as well. Since exhaustive searches may quickly grow in complexity (e.g., for NP problems), most artificial intelligence (AI) programs introduce heuristics to prevent the search from traversing the entire solutions space, instead paying attention only to the most promising or interesting paths. The contribution of machine reasoning approaches is that they demonstrate that ideas considered new at the time of their creation do not require "genius" or "divine intervention", but can be drawn from basic logic inferences, namely deduction and induction.

However, machine reasoning approaches clearly have limitations. First, the researcher needs to find an idea generator to create the possible solutions space. Development of the generator algorithm per se is a tough issue for any task that cannot be defined in a narrow problem domain. In other words, BACON and PROSPECTOR worked because their task domains were narrow. Consequently, differences across knowledge domains make it impossible to reuse these idea generators interdisciplinarily, at least not without provision of a new knowledge domain. Second, the transformation of a knowledge representation from human-understandable to machine-understandable without information loss is also a challenge. In order to code real world problems into knowledge base form, they frequently have to be significantly reduced in size and "closed world assumptions" (e.g., Reiter, 1978) have to be made, which limit realism and richness of outcomes. Third, the approaches also illustrated that machine creativity was rather "brittle", based on knowledge base limitations, and required reverse engineering, backwards from the objective, to explain the reasoning and justify the solution. Finally, these creativity machines showed little ability to evaluate the quality of their results or judge its creativity. BACON was unable to decide, for example, which of the discovered laws were impactful and further, a new program version had to be built for each new law to be discovered (BACON.1 - BACON.5), thus severely downgrading its creative abilities. In other words, it demonstrated that the machine based approaches could generate ideas, if given a well-defined problem, but would be oblivious to knowing which of the many ideas being created were special and which were mundane. 


\subsection{Supporting group brainstorming}

Group support systems (GSS) became the first widely acknowledged systems for the support of qualitative problem solving (e.g., DeSanctis \& Gallupe, 1987; Gray, 1987) Their design was based in part on the recognition that group problem solving tasks, independent of domain, can benefit from problem structuring and process improvement techniques. Nunamaker, Applegate, and Konsynski (1987), for instance, used GSS to support planning tasks in several areas such as strategic planning, information systems design, or marketing. The underlying purpose was to amplify the gains of the group process, while minimizing process losses inherent in group work. For example, the deindividuation (e.g., anonymity) brought about by computer-mediated communication, encourages true expression without the concern of social disapproval, and equal participation avoids dominance of a specific group member or party.

DeSanctis and Gallupe (1987) delineated a systematic hierarchy of group decision support systems (GDSS). Based on the information-exchange view of group decision making, three support levels were identified: (1) as communication medium to remove common communication barriers, (2) as a tool set, e.g., with planning or modeling tools, to assist the process professionally and efficiently, and (3) as a process structuring mechanism, introducing rules into systems to make the process more structured, automated and intelligent. Taking the specific contextual features such as group size or task type into account, GDSS could be designed flexibly across these three levels.

While the scope of group support systems has been enhanced significantly, the process support for (relatively small group) meetings (Dennis, George, Jessup, Nunamaker, \& Vogel, 1988) has remained as one of the key elements of group decision support systems, allowing activities such as independent, parallel problem solving, anonymous joint brainstorming, or joint, open problem solving. GSS demonstrated that by reducing process losses and amplifying process gains, we can enhance innate group abilities, leading to more creative ideas. However, due to the attributes of the group itself, the creativity displayed by a group is still limited by group member abilities, even if group support systems perform perfectly to achieve maximum process improvement. Furthermore, members of GSS groups have been found to be alike in terms of age, gender, beliefs and opinions (Aronson, Wilson, \& Akert, 2007), thus leading to undesirable effects demonstrated as groupthink-effect (Janis, 1972), as well as productivity deficits, or collaborative fixation (Kohn \& Smith, 2011). Since diversity is considered as an essential characteristic to lead to better group performance (Page, 2008), the group norming (Tuckman, 1965) related negative effects on diversity may be harmful to the development of idea variety and thus to creativity.

Unfortunately, GSS also did little to uncover the mechanisms underlying creative thinking that would allow enhancement beyond group process improvement. With the unit of analysis being the group, attention has been largely fixed to group process improvement and group outcomes, so that the underlying individual creative thinking mechanisms are remained understudied. Thus, while some measurable improvements in creativity were achieved, the outcomes were of moderate value.

\subsection{Supporting individual idea generation}

Software systems for individual idea generation and creativity support have focused largely on engaging individuals in a creative process based on known creativity principles. Individuals are encouraged to perform independently, and to employ relevant individual creativity skills, such as breaking one's perceptual and cognitive set, exercising divergent 
thinking and delayed judgment, all of which are considered to be useful to promote the creativity of individual performance (Elam \& Mead, 1987).

Elam and Mead (1990) investigated the link between individual creativity and software, and maintained that creativity-enhancing decision support systems (DSS) could guide users to follow a stepwise decision-making process instead of engaging in a single step (holisitic process) without software, identified by a sudden eureka effect. MacCrimmon and Wagner (1991/92) targeted the user interface as a determinant for idea generation success, providing structure and stimuli through standard screen configuration to enhance individual problem solving with creativity. Shibata and Hiro (2002) concentrated on non-intentional idea generation by combining problems and ideas management with personal information records. All these studies focused predominantly on the environment the computer creates for an individual problem solver. This environment was characterized, in part, by problem structuring and decision making techniques, techniques that provide stimuli and process models otherwise found only in an outside environment, as well as idea recording and evaluation techniques.

Developments in this area have demonstrated the ability to stimulate individuals to become more creative, but have also shown that innate individual creativity often overshadows the technology contribution, and that little can be done for individuals who demonstrate little creativity themselves (MacCrimmon \& Wagner, 1994; Marakas \& Elam, 1997). Marakas and Elam for instance determined that a significantly higher level of creativity enhancement for an individual would not be effective without that individual's awareness of the process model and intentional application of such process (Marakas \& Elam, 1997). In other words, the effect of creativity support on individual idea generation highly depends on the process embedded in the technology vis-à-vis the individual's perception of the process. Such dependency on individual innate abilities eventually lessens the power of technology to enhance the creativity of individual idea generation. Furthermore, judgment of which resulting ideas are in fact creative, can be beyond the ability of the individual using the technology. Since self-assessments are found to be unreliable, consensual assessments become the prevailing technique to judge creativity of ideas, which are subjective as well. In summary, then, creativity support that purely focuses on the individual, still has to contend with limitations, namely the lack of innate creative abilities, the lack of process understanding, and the ability to judge results.

\section{Extracting creativity from collective intelligence through social media}

The previous section identified strengths as well as shortcomings of prior attempts to build creativity support systems. Table 1 summarizes the shortcomings, which affect three process areas: need (problem) identification, idea generation, and idea evaluation. As outlined, no single approach can address all the challenges of creativity. Especially a replacement of the not yet understood process of creative idea generation remains a great challenge. Consequently, this research takes a different approach, away from attempting to build systems that automate creativity or enhance the creativity of individuals and small groups. Instead, the proposed alternative is to draw on innovation networks of people, and exploit their collective intelligence, elsewhere referred to as social creativity (Fischer \& Giaccardi, 2007). The underlying rationale for considering the "power of the collective", is the assumption that with a large number of people put to the task, there is enough breadth and depth in problem solving ability of the collective, so that individual and group limitations become immaterial. An analog to this logic was described by Linus Torvalds (Raymond, 1999) with respect to debugging software. Torvalds proclaimed that 
"given enough eyeballs, all bugs become shallow", or in other words, a large enough collective will find the source of all software bugs. This belief has found empirical support in the success rates of opensource software (e.g., English \& Schweik, 2007; Mockus, Fielding, \& Herbsleb, 2002).

Table 1

Limitations of creativity support systems

\begin{tabular}{|l|c|c|c||l|}
\hline & $\begin{array}{c}\text { Machine } \\
\text { Reasoning }\end{array}$ & $\begin{array}{c}\text { Group } \\
\text { Support }\end{array}$ & $\begin{array}{c}\text { Individual } \\
\text { Support }\end{array}$ & $\begin{array}{l}\text { Collective Intelligence } \\
\text { Solution }\end{array}$ \\
\hline $\begin{array}{l}\text { Need } \\
\text { Identification }\end{array}$ & $\bigotimes$ & $\square$ & $\square$ & $\begin{array}{l}\text { Search for non-existing } \\
\text { ideas }\end{array}$ \\
\hline Idea Generation & $\square$ & $\bigotimes$ & $\square$ & $\begin{array}{l}\text { Idea forges, open } \\
\text { innovation }\end{array}$ \\
\hline Idea Evaluation & $\bigotimes$ & $\square$ & $\bigotimes$ & Prediction markets \\
\hline
\end{tabular}

The collective intelligence arising from a large number of participants and diversity in the network is expected to lead to innovative needs identification, to new ideas and to the quick development and test of those ideas. As illustrated in Fig. 1, the way we propose to use the networks is three-fold: (a) to let them guide the search for non-existing ideas, i.e., help to identify new products for which there is a need; (b) to let networks of people develop new innovations for which there is a need in "idea forges"; and (c) to help with the selection of most innovative products (product winners) using collectives through prediction markets.

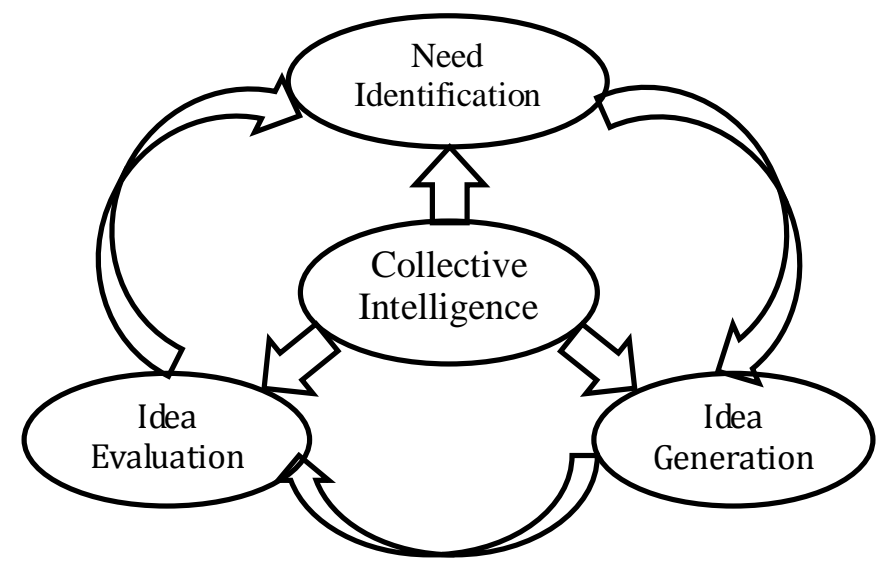

Fig. 1. A three-pronged approach for creativity support

\subsection{Collective versus group intelligence}

Collective intelligence research stresses the ability of collectives, not groups, to exhibit superior judgment. Even though collectives and groups are both composed of individuals, their aggregate characteristics are different (e.g., Surowiecki, 2005; Page, 2008). Drawing on Surowiecki (2005), Watkins (2007), and Brewer (1993), key differences between groups and collectives are summarized in Table 2. Groups are frequently referred to as 
"social aggregates that involve mutual awareness and potential mutual interaction; hence, they are the social aggregates that are relatively small and relatively structured or organized" (McGrath, 1984, p.7). Size, however, appears to matter less than the interactive nature of the relations among members (Shaw, 1976; McGrath, 1984), as well as the formative process (Tuckman, 1965), which creates the structures that enable group interactivity yet also reduce diversity. As a result of their organization and interactivity, groups have advantages in a number of tasks. Yet the relationships between members and the desire to maintain group cohesion can have negative effects, including reasoning biases such as group polarization (Janis, 1982) and representativeness fallacy (Argote, Devadas, \& Melone, 1999), induced for instance by group members' desire to imitate each other (Newell \& Simon, 1972).

Table 2

Characteristics of groups and collectives

\begin{tabular}{|c|c|c|c|}
\hline \multicolumn{2}{|r|}{ Group } & \multicolumn{2}{|c|}{ Collective } \\
\hline \multirow{3}{*}{$\begin{array}{l}\text { Homogeneous } \\
\text { nature }\end{array}$} & $\begin{array}{l}\text { Mimicry among } \\
\text { members }\end{array}$ & \multirow{3}{*}{$\begin{array}{l}\text { Heterogeneous } \\
\text { nature }\end{array}$} & $\begin{array}{l}\text { Diversity in members' } \\
\text { opinions }\end{array}$ \\
\hline & $\begin{array}{l}\text { Dependence in } \\
\text { decision making }\end{array}$ & & $\begin{array}{l}\text { Independence in } \\
\text { decision making }\end{array}$ \\
\hline & $\begin{array}{l}\text { Centralization of } \\
\text { resources }\end{array}$ & & $\begin{array}{l}\text { Decentralization of } \\
\text { resource and } \\
\text { knowledge }\end{array}$ \\
\hline \multicolumn{2}{|c|}{$\begin{array}{l}\text { Experts can sway the group's opinion } \\
\text { and are important in the system (e.g. } \\
\text { Expert system). }\end{array}$} & \multicolumn{2}{|c|}{$\begin{array}{l}\text { Experts have little way of influencing the } \\
\text { outcome and thus may not be critical for } \\
\text { the performance of the collective. }\end{array}$} \\
\hline
\end{tabular}

Collectives differ from groups through their heterogeneous nature owing to the diversity among group members, the independence among members in decision making, and the decentralization of resources and knowledge (Surowiecki, 2005). First, diversity of opinion refers to the availability of multiple viewpoints. Diverse perspectives represent different ways of perceiving situations; by virtue of being different, individuals can improve upon each other's solution approach to a problem (Hong \& Page, 2004). By utilizing a population that holds different pieces of information, a clearer presentation of the whole picture emerges. Second, independence means that peoples' opinions are not determined by the opinions of others. The lack of group structure in collectives allows people to make decisions independently and to voice opinions freely. In contrast, the members in a group setting (without GSS) tend to be influenced by others, especially experts and authorities. Sharing among participants in collectives is relatively more open and less likely to be biased (Berger, Webster, Ridgeway, \& Rosenholtz, 1986). Based on the independent views available in collectives, aggregate views tend to be accurate, in fact even more accurate than experts' opinions (Ashton, 1985; Wolfers \& Zitzewitz, 2004). Third, the decentralization characteristic implies that decisions "are made by individuals based on their own local and specific knowledge rather than by an omniscient or farseeing planner" (Surowiecki, 2005, p. 71). This is relevant to the diversity of solution finding heuristics (Page, 2008). In collectives, the individuals independently choose when and what to participate, while the participation tends to be more structured and less flexible in traditional groups. 
While diversity, independence, and decentralization are conditions necessary for collective intelligence, they cannot explain why collectives perform better. Furthermore, the obvious assumption of having many "processing units" available also does not suffice as an explanation. After all, many people generating the same ideas collectively do not produce new ideas. The ability of collectives is thus not simply a manifestation of the Law of Large Numbers (Bernoulli, 1713), but the existence of a variety of rival theories about a phenomenon among members of the collective, leading to numerous different approaches on how to find solutions to the same problem. Several criteria have to be met to make this process effective (Page, 2008). The collective must therefore approach the problem with different mechanisms so as not to replicate the same elimination mechanism again. In other words, the crowd needs diversity (Page, 2008).

When comparing the creative abilities of collectives over groups, we must not forget that they have considerable similarities, chief among them the fact that multiple people, in aggregate, are tasked to find novel and useful solutions to a problem or need. Collectives may be more akin to nominal groups (Delbecq, Gustafson, \& Van de Ven, 1975 ) yet may nevertheless inherit some of the productivity deficits of groups (Kohn \& Smith, 2011), and thus benefit from improvements facilitated by group support systems. Thus, although participants in a collective work individually and operate like a nominal group, the open and transparent collaboration platform cannot absolutely eliminate the effects of others' ideas or opinions during the process of collaboration.

The counter-productive effects of interaction within the collective are responsible in part for negative views of collective intelligence. While some refer to the wisdom of crowds (Surowiecki, 2005), others cite the madness or stupidity of crowds (MacKay \& Schneider, 2004; Steiglitz \& Shapiro, 1998) as illustrated in traffic congestion, bubble markets, or information cascades, thus raising concern about the ability of crowds to perform reliably. Hence, in analyzing the creative ability of collectives, we need to be sensitive of crowd abilities as well as limitations, and address those limitations through information technology. To some extent, we expect large collectives can minimize the recognized negative consequences associated with collective collaboration as long as the collective is equipped with sufficient diversity, independency and decentralization (Page, 2008). Assuring this, in part, will be the role of creativity support systems for collectives.

\subsection{Social media}

Advances in information technology have enabled a form of virtual content exchange in cyberspace through a variety of web-based functionalities powered by the read-write web (Murugesan, 2007). Transferring from content receivers in Web 1.0, Internet users now are also acting as content creators and modifiers who work globally in a collaborative manner. Build upon the platform of Web 2.0, User Generated Content (UGC), which refers to the various forms of media content that are publicly available and created by end-users (Kaplan \& Haenlein, 2010), rapidly spreads across the Internet, drawing increased attention. According to Organization for Economic Cooperation and Development (OECD 2007), publicly published media content needs to show a certain amount of creative effort in order to be considered as User Generated Content.

The definition of social media draws on the concept of UGC, considering for instance Kaplan and Haenlein's (2010) description as “a group of Internet-based applications that build on the ideological and technological foundations of Web 2.0 and that allow the creation and exchange of User Generated Content". According to this broad definition, a myriad of Internet-based applications can be considered as social media, including obvious ones such as Wikipedia, Facebook, Twitter, or Digg, as well as 
various virtual communities of practice, or special purpose networks such as software forges or prediction markets.

To further organize the broad range of social media applications, Kaplan and Haenlein (2010) developed a feature-based categorization scheme that classifies different types of social media. The categorization draws on theories of media research (social presence, media richness) and social processes (self-presentation, self-disclosure), the two key elements of Social Media. Table 3 identifies six kinds of social media according to Kaplan and Haenlein's (2010) classification.

Table 3

Social media classification based on Kaplan and Haenlein (2010)

\begin{tabular}{|c|c|c|c|c|}
\hline \multicolumn{2}{|c|}{} & \multicolumn{3}{|c|}{ Social presence/Media richness } \\
\cline { 2 - 5 } \multicolumn{2}{|c|}{} & Low & Medium & High \\
\hline \multirow{2}{|c|}{$\begin{array}{c}\text { Self- } \\
\text { presentation } \\
\begin{array}{c}\text { /Self- } \\
\text { disclosure }\end{array}\end{array}$} & Low & Blogs & $\begin{array}{c}\text { Social networking } \\
\text { sites (e.g., Facebook) }\end{array}$ & $\begin{array}{c}\text { Virtual social worlds } \\
\text { (e.g., Second Life) }\end{array}$ \\
\cline { 2 - 5 } & $\begin{array}{c}\text { Collaborative } \\
\text { Projects (e.g., } \\
\text { Wikipedia) }\end{array}$ & $\begin{array}{c}\text { Content communities } \\
\text { (e.g., YouTube) }\end{array}$ & $\begin{array}{c}\text { Virtual game worlds } \\
\text { (e.g., World of } \\
\text { Warcraft) }\end{array}$ \\
\hline
\end{tabular}

\subsection{Focus on creativity support in the business environment}

Instead of broadly focusing on creativity in general, the remainder of the article will target creativity in the business environment, with special focus on new products and their development. New product development requires originality, but at the same time must be relevant and focus on customer needs. Furthermore, new products must be implementable. Considerable research effort has gone into the study of new product development and the role of individuals, groups, and nominal groups in the process (e.g., Dalkey, 1969; Lilien, Morrison, Searls, Sonnack, \& Von Hippel, 2002). Thus new product development will be an ideal application area to explore the role of collectives and of technology support.

\subsubsection{Problem finding (Need identification)}

Coming up with new product ideas is oftentimes not as much a process of blue ocean invention, but instead an understanding of not yet met customer demands. Being "new to the market" is one of the most important success criteria for new product ideas (Cooper, 1979), yet it does not mean the idea must be new to the world. In fact, the study of disruptive innovations has shown that the disruptiveness arises from an understanding of unmet customer needs, and the trade-off against over-satisfied needs (cf. Christensen \& Overdorf, 2000).

Traditionally, identifying unmet product needs was a process which involved customer interviews, focus groups, or close collaboration with lead users, approaches that are all focusing on a narrow customer group available to the market researchers. Social media, however, changes the reach of market research and enables a much broader needs elicitation approach. Given the right tools, it should be possible to identify needs that suggest new product ideas from a broad and diverse user base. The task thus becomes one 
of exploring what customers are talking about and which non-existent products they are seeking. Proposition 1 (1a and $1 \mathrm{~b}$ ) formally frames this understanding:

Proposition 1a: People will search for new product ideas using social media even if these products do not yet exist.

Proposition 1b: People will discuss new product ideas using social media even if these products do not yet exist.

Proposition 1 may be questionable at first, as one would rather expect customers to talk about existing ideas, or features and benefits that an existing product does not provide. It is our contention, however, that social media will provide access to enough people who can phrase their needs in terms of new feature bundles that become products, instead of simply referring to unmet needs.

Much of this information will likely be buried under the noise of the Internet, and hence the challenge will be to extract it. For example, if an individual blogger expresses the need or suggestion for a new method to dispose rubber tires, the thought may pass unnoticed by the tire companies who could have effectively addressed it. Hence, the challenge is, at least in part, to extract the collective intelligence, and reveal it as a meaningful signal within the noise of the Internet.

Evidence suggests that this can be done and that it is a meaningful technique for idea finding (Thelwall \& Hasler, 2007). An example may illustrate this. Google Trends (http://trends.google.com) is an application that aggregates the search behavior of the entire Google audience (or subsets) over time. Using Google Trends, we can retrieve data about the popularity of search terms within Google over time. Google Trends plots the results in graphical form. Fig. 2 shows a graphical representation of the search for "iPhone 6" with Google Trends.

We purposely chose to trend iPhone 6 because it does not yet exist and thus represents a not yet met customer need. Yet, surprisingly, even though the sixth generation iPhone has not been launched at present, search for it on Google began in late 2006 and has seen rapid growth. In other words, Google search engine users appear eager to learn about an Apple product several years before its expected launch. Interestingly enough, not only the search behavior can be observed, but also attempts at new design concepts of "iphone 6" emerged on the web, such as http://www.conceptphones.com/apple/iphone-6-concept-takes-future/.

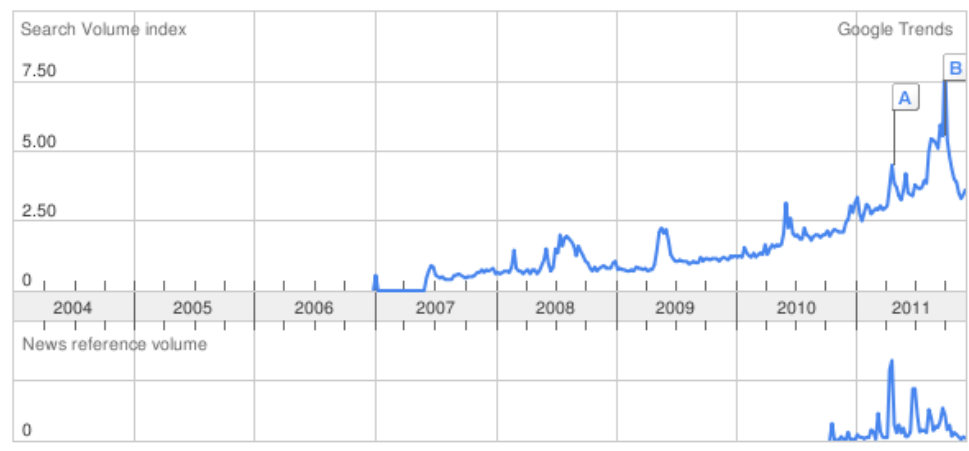

Fig. 2. Google trends tracking of search interest for "iPhone 6" 
There may be an objection to this argument, as Google Trends is not a social medium by narrow definition. Clearly, a crowd did not come together to voice its need actively, but instead individuals issued Google searches. However, inasmuch as user queries are user generated content and Google Trends provides a platform for their exchange, Google Trends is a social medium according to Kaplan and Haenlein (2010). Furthermore, Google Trends is just one manifestation of this social media search aggregation ability. Technorati (http://technorati.com) performs a similar task in the blogosphere, monitoring and trending the key words people assign to their blog articles on the Internet. The trending observed previously in online searches and weblogs has become even more prevalent in today's highly interactive social media sites such as Facebook or Twitter, with their collective user base of more than 1 Billion people. As a result, when posts and conversations on these social media platforms are drawing attention from global crowds, trends indicating users' underlying needs and interests spread widely and quickly, and can be tracked. Tweetmeme (http://tweetmeme.com) may serve as an example for the Twitter collective. With approximately 340 million tweets posted daily as of March 2012 (http://blog.twitter.com/2012/03/twitter-turns-six.html), Tweetmeme attempts to find the most popular "stories" by aggregating popular posts that are topically related. Furthermore, tweetmeme also classifies these popular links into different categories based on channel and theme so that noise can be filtered out. Similar Internet-based applications exist for Facebook (e.g., Booshaka, or Facepinch). This trending of vast numbers of postings produces great diversity, but also allows the detection of even nascent trends, as long as the aggregation mechanism provides suitable filtering mechanisms. It is noteworthy, that the Twitter trending mechanism is named Tweetmeme, referring to the term meme, originally proposed by the British evolutionary biologist Dawkins (1976). A meme, according to Dawkins, is an idea, behavior or style that spreads from one mind to another through writing, speech, gestures, rituals or other imitable phenomena. Internet memes such as tweetmemes thus are ideas or concepts spreading and evolving over the Internet, whether by chance or through commentary, forwarding, search, or other means. Within the context of this research, we can consider Internet memes to be expressions of shared interests and potentially shared needs. In addition to keyword searches and post aggregation, other mechanisms for needs extraction from social media exist. For example, at Clemson University, a Social Media Listening Center (SLMC) enables students to monitor thousands of online conversations about organizations, brands, products and services on a global scale in real time, and allows for more sophisticated review, routing and response to social media posts and content (http://cyberinstitute.clemson.edu/projects/42). Furthermore, companies increasingly build platforms for their customers to express needs or "design" their own products (cf. http://radian6.com), serving as a reminder that the use of memes is not only limited to need elicitation, but that it can also serve for idea generation and idea evaluation.

The characteristics of the user collective, namely diversity, independence and decentralization, appear to positively affect the creativity of the need identification activity. Social media enable search and discussion about scattered and divergent topics, which yields ideas in various fields, even in little known areas (originality). The independency of the collective, to some extent, avoids information cascades, while well designed social media engines keep the public from being misled by minorities. In Slashdot, for instances, people can rate the quality of others' comments, thus allowing them to be more or less prominent. To do so, however, requires "karma" from previous contributions, and this karma is spent in the moderation process. Comments can be categorized during this moderation process, for instance as insightful or interesting, thus further informing the process. 


\subsubsection{Asset creation (Idea generation)}

Idea generation clearly is the most difficult part of the creative process, the one that is least plannable. Our prior observations from creativity support software also suggest that it remains largely a black box to date. While some successes have been achieved with support tools, a more promising approach appears to be to harness the diverse views on many and use them to create innovative knowledge assets, without understanding in detail the source of this collective creativity.

The resulting process has been referred to as open sourcing the innovation process or as open innovation, borrowing from the concepts of open source software development (Markus, Manville, \& Agres, 2000). The underlying idea is that by revealing the idea generation challenge to many people, many different approaches can be brought to bear, thus leading to a broad range of new ideas. This has been described for instance in the context of the Goldcorp challenge (Surowiecki, 2005) whereby the Goldcorp corporation revealed a vast amount of geological information and successfully drew on the insights of many to suggest new ore deposits.

One of the attractive opportunities for open innovation is that it can draw on vast volunteer resources. To illustrate, according to Nielsen (2010), the global traffic to social networking sites measured 313.7 million persons in March 2010, who in total spent 113.1 billion minutes (1.9 Billion hours) on these sites, or 10.7 million person-months. In other words, total social website user activity equalled a workforce of over 10 million full-time knowledge workers willing and able to volunteer their time. This is a very significant supply of knowledge workers, which ideally can be channelled into more meaningful tasks than reading and updating daily gossip on Facebook pages. We thus formulate a second proposition for creativity support through collective intelligence.

Proposition 2: Collective intelligence can transform the process of innovative idea asset creation through open models of collaboration and access to a large and diverse contributor base.

An example of this approach is illustrated in Fig. 3 and Fig. 4. The figures show partial screen shots from the Redesignme (http://redesignme.com) open innovation site. Redesignme, like several other sites of its kind have some individuals or companies post an innovation challenge (Fig. 3), inviting innovators to respond, usually with the promise of financial reward.

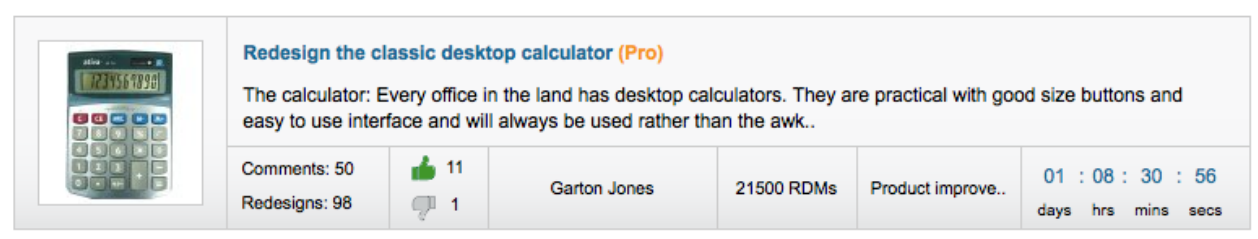

Fig. 3. Open innovation design challenge on Redesignme.com

Responses are collected within the system and made available for comment or for rating (Fig. 4). As the challenge continues, new design suggestions can take advantage of the feedback and create further improvement. This process results in a number of options, the best of which are frequently quite creative. Why does this work? Here again, the approach does not explore the black box of creativity any further, but in novel ways draws on the imagination of a large collective to suggest ideas and improve on suggestions. In particular, such sites can take advantage of broader expertise than normally available in R\&D labs. The CEO of Goldcorp for instance commented that his 
firm's "Goldcorp challenge" attracted a broad range of participants from many backgrounds, using many approaches to prospecting that the company had never seen (Clayton, 2002). A similar approach to creativity is used in techniques which create connections between known and unfamiliar scenarios, to transfer knowledge from one to the other, for instance through a metaphorical process, as done in Synectics (Gordon 1961).
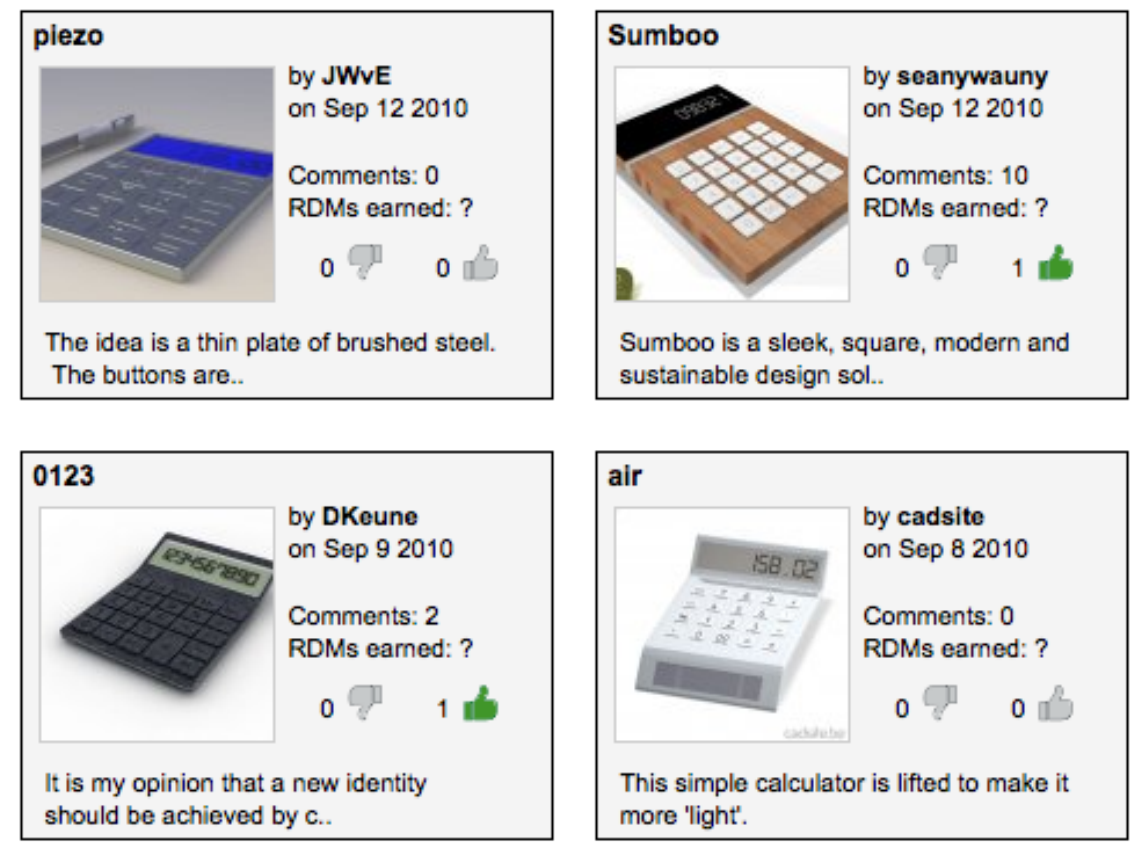

Fig. 4. Designer responses with feedback

In addition to the illustration in Fig. 3 and Fig. 4, there are many other applications of collective intelligence for idea generation, taking advantage of "crowdsourcing" (Howe, 2008). Threadless, for instance is an online design community and e-commerce site that weekly sources new designs, and then puts them up for vote. InnoCentive, is an open innovation company looking for solutions to difficult scientific problems globally. Solutions are vetted by experts and rewarded. Many of these crowdsourcing websites also tap into social media platforms, including Facebook and Twitter in order to attract more problem solvers and ideas, and nurture social relationships with customers (e.g., http://twitter.com/\#!/threadless).

As with many open source projects, here, the success of results cannot be guaranteed. First of all, not all open source projects can attract enough eyeballs to participate in idea generation, especially at the outset. Second, because of the loose relationship between the problem raisers and solvers, solvers have no responsibility to ensure the quality and further maintenance of ideas. This makes it difficult to sustain the prosperity of active idea submission. Next, since the ideas are displayed openly, everyone on the Internet can get access to them, which probably results in competitors' free riding. However, in contrast to closed development approaches, shortcomings are quickly identified, while a large pool of contributors offers a wide range of approaches to finding new ideas, which can also overcome concerns about free riding. The large size of collective makes it possible to gather a larger number of solutions through an open call, 
especially compared with traditional forms of hired labor. The diversity of collective contributes to make ideas heterogeneous, providing multifarious mechanisms to solve the same problem and increasing the proportion of ideas with higher level of originality. Independent participants are more likely to rely on their private information rather than uniformly following others' thoughts during the process of idea generation, which likely yields original ideas instead of meaninglessly replicated ideas. Decentralized collectives always take into account their local scenarios while generating ideas. In that case, ideas can be fitted into practical context well so that their purpose and implementability can be ensured. Hence, it can be inferred that the collective intelligence approach is able to improve the creativity of idea generation on the basis of our modest definition.

\subsubsection{Success measurement (Creativity assessment)}

When it comes to the assessment of creativity in product development this translates into the possible success of new product ideas. Traditionally, making such assessments has been difficult and error prone. However, with collective intelligence, this activity can be facilitated. Not only will a collective be able to detect problems "bugs" within a product idea, according to Linus's Law (Raymond, 1999), but also will be able to assess the value within the idea market place. Thus, a third proposition for creativity support through collective intelligence is:

Proposition 3: Collective intelligence can identify idea quality through the collective detection of failure criteria and success criteria.

Earlier examples of solution voting within sites such as threadless.com or innocentive.com have hinted at the possibility of success measurement. In addition, other approaches have been developed which conceptualize the problem as a "market of ideas" and let market trades serve as proxy for success. Among these approaches, prediction markets have shown to be effective. A prediction market is a market where uncertain events are traded (Wolfers \& Zitzewitz, 2004). "Will Boeing's 787 jet be delivered before the end of 2010?" would be a typical question such a market would ask. The logic of prediction markets is based on the aggregation of participant information, whereby people choose how much money to risk on a prediction, and consequently reveal their likelihood estimation for that event. The aggregation of these individual choices then is supposed to reveal a highly accurate prediction. Prediction markets are not unlike existing stock markets, yet they only deal in intangibles and usually cover events not covered by existing exchanges.

The use of prediction markets has been demonstrated to forecast the uncertain events better than other prediction methods, such as forecasting, focus groups, or expert interviews (cf. Servan-Schreiber, Wolfers, Pennock, \& Galebach, 2004). One longrunning and highly successful example has been the Hollywood Stock Exchange (HSX). The HSX is not a real stock exchange, but an online market that uses a fictional currency to deal in (the success of) movies. Participants can purchase shares in movies or prior to their release and then gain a profit if the movie succeeds, or lose their investment if the movie fails. The HSX also predicts events such as American Idol. Fig. 5 demonstrates this, with the stock performance for Jodine Sparks. Sparks, the 2007 winner, doubled investor "stock value" from $\$ 12$ to $\$ 24$.

HSX has emerged as a valuable product for media companies to tweak their product offerings, choose the number of movie theatres through which to launch a movie, or to adjust their marketing strategy. In fact, HSX has been so successful that currently the owners are seeking to turn it into a for-money trading site, thus truly monetizing 
participation for its participants. Elsewhere prediction markets such as NewsFutures or Inkling are already used by corporations to support their product evaluation process, including applications in the pharmaceutical, automotive, and publishing industry.

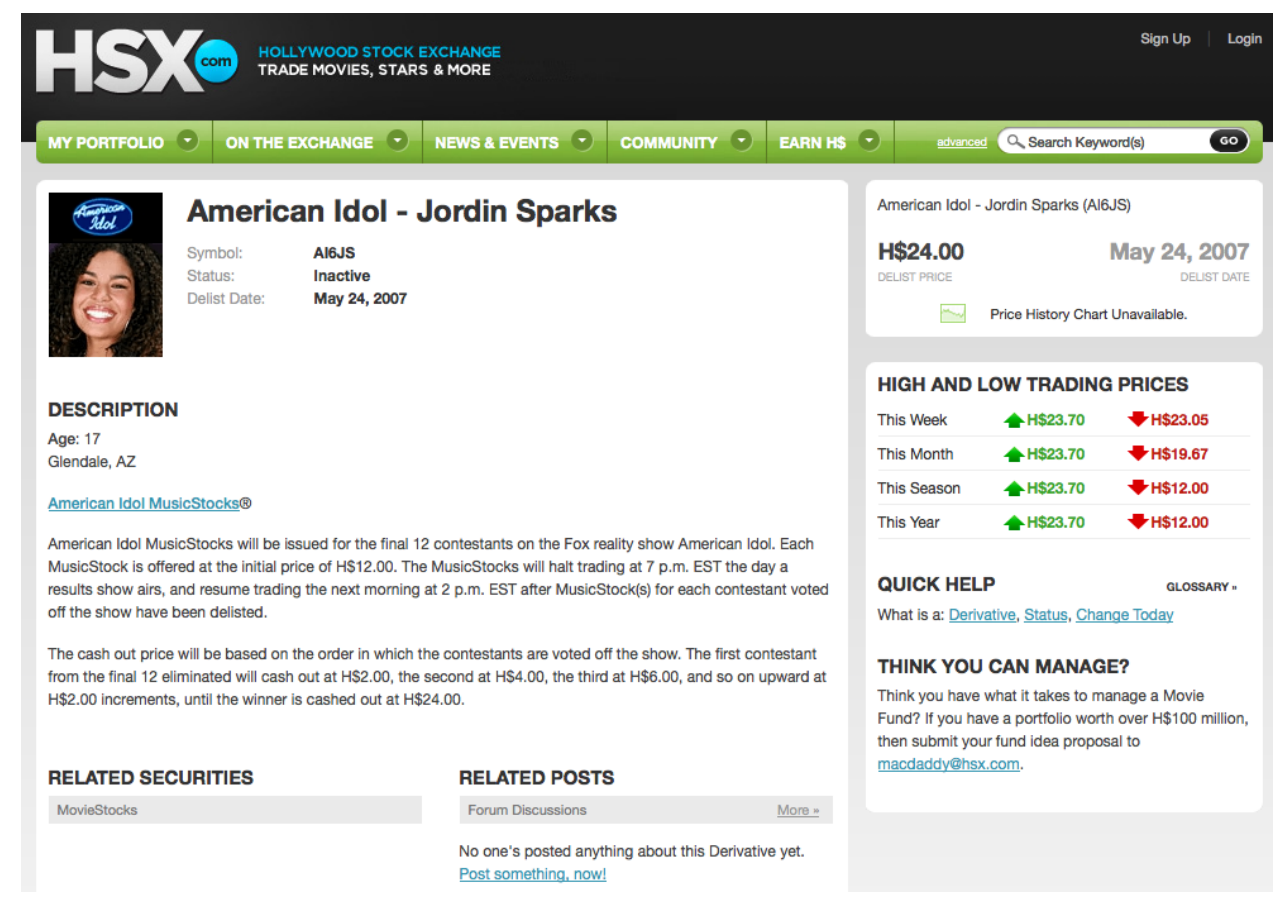

Fig. 5. HSX prediction market stock performance

Similar (although less sophisticated) evaluation strategies are occurring on many social media sites, including Facebook, Twitter or Wikipedia. Facebook users, for instance, can express their positive attitude towards posts by clicking the Like button. Through monitoring the accumulation of likes for individual posts in Facebook, a webbased application, likebutton.com, constantly updates the real-time top posts which are popular in a specific category globally and socially on the Internet. Twitter uses mediaspecific features to express preferences, such as the Retweet button and Favorite button. Tweets with large Retweet or Favorite counts are likely to be highly favored ones. Wikipedia, asks for even more explicit evaluations of quality, with its ratings "Rate This Page" feature. In fact, rating may be the best-executed feature in social media related to creativity support, as the vast majority of popular social media sites now appears to include one or another voting mechanism. While participants of prediction markets such as the HSX intend to earn fictional currency through their predictions, volunteers elsewhere, such as Facebook likers, Twitter followers, and Wikipedia raters readily evaluate ideas without any apparent rewards.

Overall we also expect the idea evaluation mechanism to benefit from collective diversity, independence and decentralization afforded by the size and reach of social media sites. Even though the voting behaviors take many forms, all of them are delivering the voice of assessment, yet with different criteria. The diverse voting mechanisms (e.g., success of movies, relevance of web pages, correctness of articles in Wikipedia, the preference of t-shirt designs), can evaluate ideas from different perspectives and let ideas with high level of originality, implementability and purpose 
stand out, thus breaking through the limitations of self-report and expert-consensus for idea assessment. Here in particular the independence of the collective should rule out the interference of others' views, and make evaluation more rational instead of skewed by the voice of authority or majority (we note that for instance in the case of Digg, a minority group of editors for a while tried to bias results, but then was stopped by the collective (Owens, 2008)). Thus, it appears that the decentralized collective can readily evaluate ideas based on its own knowledge and resources. Apart from adopting consensual or authoritative criteria, collective can also empirically test alternative solutions based on their local knowledge, thus raising the rigor of requirements for idea purpose and implementability.

\section{Discussion and conclusion}

Social media are promising a transformative approach to elicit people's needs, to capture innovative ideas, and to make sound assessments. While some people contribute knowledge to the repository of social media intentionally, such as the solvers of Redesignme, some present their opinions unintentionally such as viewers of Wikipedia or searchers using the Google engine. The potential power of people's collective behaviors in social media, e.g., searching, blogging, and browsing, thus becomes available to serve creativity enhancement in three processes, locating problems in need of creative solutions, generating creative ideas for identified problems, and evaluating the degree of creativity for ideas. With the help of technology based tools, the triple combination of search result aggregation for idea finding, idea forges for open innovation and creative idea development, and prediction markets for the assessment of innovative ideas, closes the loop on creativity support through collective intelligence. Together they suggest an opportunity to cover the three key challenges of creativity support not addressed by prior approaches. Our discussion in this article has demonstrated that the dimensions of creativity in our definition - originality, implementability and purpose — can be enhanced with respect to these three processes due to the diversity, independence and decentralization of collectives in social media.

The collective intelligence approach to creative problem solving is also confronted with challenges in these three aspects. For need identification, the challenges include how to choose the indicative behaviors in social media (e.g., web searching, social networking, and e-commerce) as information resources, how to extract meaningful signals from the noise, and then how to deliver the information to those who value it. In regards to idea generation, as Nielsen (2010) reports, even though there is a vast amount of volunteer resources on the Internet, most of the Internet users are prone to spend their time on social networking sites on fun activities, instead of more meaningful tasks. Thus, it is critical to attract more attention to expand the contributor base and keep contributors' abiding participations. As far as idea evaluation is concerned, corporations are cautious to involve the public to make decisions for them, when products are proprietary. This is one of the reasons why some companies hold idea evaluation in a limited scope. For instance, even though Goldcorp took a radical step by making its private geological information known to the public and host the online competition "Goldcorp Challenge", it nevertheless invited an independent panel of recognized geological experts to evaluate and rank the submissions (Clayton, 2002).

Despite these shortcomings, collective intelligence suggests interesting new directions for creativity support, which has remained as one of the tough challenges for computational approaches. This research has highlighted some of the new directions, which circumvent the shortcomings of existing approaches and given suggestions 
concerning their potential effectiveness. As a result, we are proposing to substitute or supplement poorly understood processes of creativity through "artificial" creativity harnessed from the collective intelligence of many. In other words, the processes that create the phenomenon of creativity remain a black box, yet by energizing enough members of the collective, we expect to repeatedly find enough of the phenomenon to create a replicable process of innovative solution finding.

\section{Acknowledgements}

The work described in this paper was substantially supported by a grant from the Research Grants Council of the Hong Kong Special Administrative Region, China (Project No. CityU 150811).

\section{References}

Argote, L., Devadas, R., \& Melone, N. (1999). The base-rate fallacy: Contrasting processes and outcomes of group and individual judgment. Organizational Behavior and Human Decision Processes, 46(2), 296-310.

Aronson, E., Wilson, T. D., \& Akert, R. M. (2007). Social psychology (6th Ed.). Lebanon, Indiana: Prentice Hall.

Ashton, A. H., \& Ashton, R. H. (1985). Aggregating subjective forecasts: Some empirical results. Management Science, 3(12), 1499-1508.

Berger, J., Webster, M., Ridgeway, C., \& Rosenholtz, S. J. (1986). Status cues, expectations and behaviors. Greenwich, CT: JAI Press.

Bernoulli, J. (1713). Ars conjectandi: Usum \& applicationem praecedentis. In D. Civilibus (Ed.), Moralibus \& Oeconomicis (Chapter 4).

Bessemer, S. P., \& Treffinger, D. J. (1981). Analysis of creative products: Review and synthesis. Journal of Creative Behavior, 15(3), 158-178.

Brewer, M. B. (1993). Social identity, distinctiveness, and in-group homogeneity. Social Cognition, 11(2), 150-164.

Choi, H., \& Varian, H. (2009). Predicting the present with Google trends. Google Research. Retrieved

from http://ec.europa.eu/bepa/pdf/seminars/google_predicting_the_present.pdf.

Christensen, C. M., \& Overdorf, M. (2000). Meeting the challenge of disruptive change. Harvard Business Review, March-April, 1-11.

Clayton, G. (2002). Goldcorp's virtual prospecting innovation. Retrieved from http://www.camese.org/uploads/goldcorp-fin.PDF.

Cooper, R. G. (1979). The dimensions of industrial new product success and failure. Journal of Marketing, 43(3), 93-103.

Dacey, J. S. (1989). Fundamentals of creative thinking. Lexington, MA: Lexington Books.

Dalkey, N. C. (1969). The Delphi method: An experimental study of group opinion. RAND Research Memoranda, Report No RM-5888-PR.

Dawkins, R. (1976). The selfish gene. USA: Oxford University Press.

Dean, D. L., Hender, J. M., Rodgers, T. L., \& Santanen, E. L. (2006). Identifying quality, novel, and creative ideas: Constructs and scales for idea evaluation. Journal of 
Association for Information Systems, 7(10), 646-699.

Delbecq, A. L., Gustafson, D. H., \& Van de Ven, A. H. (1975). Group techniques for program planning: A guide to nominal group and Delphi processes, Management Application Series. Glenview, Illinois: Scott-Foresman,

Dennis, A. R., George, J. F., Jessup, L. M., Nunamaker, J. F., \& Vogel, D. R. (1988). Information technology to support electronic meetings. MIS Quarterly, 12(4), 591624.

DeSanctis, G., \& Gallupe, R. B. (1987). A foundation for the study of group decision support systems. Management Science, 33(5), 589-609.

Elam, J. J., \& Mead, M. (1987). Designing for creativity: Considerations for DSS development. Information and Management, 13(5), 215-222.

Elam, J. J., \& Mead, M. (1990). Can software influence creativity? Information Systems Research, 1(1), 1-22.

English, R., \& Schweik, C. M. (2007). Identifying success and abandonment of free/libre and open source (FLOSS) commons: A preliminary classification of sourceforge.net projects. Upgrade: The European Journal for the Informatics Professional, 7(6), 5459.

Fischer, G., \& Giaccardi, E. (2007). Sustaining social creativity. Communications of the ACM, 50(12), 28-29.

Howe, J. (2008). Crowdsourcing: Why the power of the crowd is driving the future of business. New York: Crown Business.

Galton, F. (1869). Hereditary genius: An inquiry into its laws and consequences. London: Macmillan/Fontana.

Gordon, W. J. J. (1961). Synectics: The development of creative capacity. New York: Harper and Row.

Gray, P. (1987). Group decision support systems. Decision Support Systems, 3(3), 23342.

Murugesan, S. (2007). Understanding Web 2.0. IT Professional, 9(4), 34-41.

Hong, L., \& Page, S. E. (2004). Groups of diverse problem solvers can outperform groups of high-ability problem solvers. In Proceedings of the National Academy of Sciences, 101(46), 16385-16389.

Jackson, P. W., \& Messick, S. (1965). The person, the product, and the response: Conceptual problems in the assessment of creativity. Journal of Personality, 33(3), 309-329.

Janis, I. L. (1972). Victims of groupthink. Boston: Houghton Mifflin Company.

Kaplan, A. M., \& Haenlein, M. (2010). Users of the world, unite! The challenges and opportunities of social media. Business Horizons, 53(1), 59-68.

Kohn, N. W., \& Smith, S. M. (2011). Collaborative fixation: Effects of others' ideas on brainstorming. Applied Cognitive Psychology, 25(3), 359-371.

Langley, P., Simon, H. A., Bradshaw, G. L., \& Zytkow, J. M. (1987). Scientific discovery: Computational explorations of the creative processes. Cambridge, MA: MIT Press.

McGrath, J. E. (1984). Groups: Interaction and performance. Lebanon, Indiana: Prentice Hall.

MacCrimmon, K. R., \& Wagner, C. (1991/92). The architecture of an information system for the support of alternative generation. Journal of Management Information Systems, $8(3), 49-67$.

MacCrimmon, K. R., \& Wagner, C. (1994). Stimulating ideas through creativity software. Management Science, 40(11), 1514-1532.

MacKay, C., \& Schneider, D. J. (2004). Extraordinary popular delusions and the madness of crowds. New York: Barnes and Noble.

Marakas, G. M., \& Elam, J. J. (1997). Creativity enhancement in problem-solving: through software or process? Management Science, 43(8), 1136-1146. 
Markus, M. L., Manville, B., \& Agres, C. E. (2000). What makes a virtual organization work? Sloan Management Review, 42(1), 13-26.

Michie, D., \& Johnston, R. (1984). The creative computer: Machine intelligence and human knowledge. London: Viking.

Mockus, A., Fielding, R., \& Herbsleb, J. (2002). Two case studies of open source software development: Apache and Mozilla. ACM Transactions on Software Engineering and Methodology, 11(3), 309-346.

Newell, A., \& Simon, H. A. (1972). Human problem solving. Englewood Cliffs, NJ: Prentice-Hall.

Nunamaker, J. F., Applegate, L. M., \& Konsynski, B. R. (1987). Facilitating group creativity: Experience with a group decision support system. Journal of Management Information Systems, 3(4), 5-19.

Nielsen. (2010). Facebook and twitter post large year over year gains in unique users. Nielsenwire, May 4, Retrieved from http://blog.nielsen.com/nielsenwire /global/facebook-and-twitter-post-large-year-over-year-gains-in-unique-users/.

Osborn, A. F. (1953). Applied imagination: Principles and procedures of creative problem solving. Buffalo, NY: Creative Education Foundation Press.

Owens, S. (2008). Digg puts focus on politics, bringing charges of liberal bias. Retrieved from http://www.pbs.org/mediashift/2008/09/digg-puts-focus-on-politics-bringingcharges-of-liberal-bias248.html.

Page, S. E. (2008). The difference: How the power of diversity creates better groups, firms, schools, and societies. Princeton, NJ: Princeton University Press.

Raymond, E. (1999). The cathedral and the bazaar. Knowledge, Technology \& Policy, 12(3), 23-49.

Reiter, R. (1978). On closed world data bases. In Gallaire, H., \& Minker, J. (Eds.) Logic and Databases. Plenum, New York, 55-76.

Ripple, R. E. (1989). Ordinary creativity. Contemporary Educational Psychology, 14(3), 189-202.

Servan-Schreiber, E., Wolfers, J., Pennock, D. M., \& Galebach, B. (2004). Prediction markets: Does money matter? Electronic Markets, 14(3), 243-251.

Shaw, M. E. (1976). Group dynamics: The psychology of small groups (2nd ed.). New York: McGraw-Hill.

Shibata, H., \& Hori, K. (2002). A system to support long-term creative thinking in daily life and its evaluation. In Proceedings of the 4th conference on Creativity \& Cognition, 142-149.

Steiglitz, K., \& Shapiro, D. (1998). Simulating the madness of crowds: Price bubbles in an auction-mediated robot market. Computational Economics, 12(1), 35-59.

Surowiecki, J. (2005). The wisdom of crowds: Why the many are smarter than the few and how collective wisdom shapes business, economies, societies, and nations. New York: Random House.

Thelwall, M., \& Hasler, L. (2007). Blog search engines. Online Information Review, 31(4), 467-479.

Tuckman, B. (1965). Developmental sequence in small groups. Psychological Bulletin, 63(6), 384-399.

Turing, A. (1937). On computable numbers, with an application to the Entscheidungsproblem. In Proceedings of the London Mathematical Society, 42(2), 230-265.

Lilien, G. L., Morrison, P. D., Searls, K., Sonnack, M., \& Von Hippel, E. (2002). Performance assessment of the lead user idea-generation process for new product development. Management Science, 48(8), 1042-1059. 
Wagner, C., \& Back, A. (2008). Group wisdom support systems: Aggregating the insights of many through information technology. Issues in Information Systems, IX(2), 343-350.

Walker, M. G. (1987). How feasible is automated discovery. IEEE Expert, 2(1), 69-82.

Watkins, J. H. (2007). Prediction markets as an aggregation mechanism for collective intelligence. Retrieved from http://www.fusedstockpredictions.com/collectiveintelligence.

Wolfers, J., \& Zitzewitz, E. (2004). Prediction markets. Journal of Economic Perspectives, 18(2), 107-126. 